Research paper

\title{
Unplanned postdischarge healthcare utilisation, discharge readiness, and perceived quality of teaching in mothers of neonates hospitalized in a neonatal intensive care unit: A descriptive and correlational study
}

\author{
Laura Rio $\mathrm{PhD}^{\mathrm{a}, *}$, Chloé Tenthorey RN, MSc(Nurs) ${ }^{\mathrm{a}, \mathrm{b}}$, Anne-Sylvie Ramelet, RN, $\mathrm{PhD}^{\mathrm{a}, \mathrm{c}}$ \\ ${ }^{a}$ Institute of Higher Education and Research in Healthcare, University of Lausanne and Lausanne University Hospital, Lausanne, Switzerland \\ ${ }^{\mathrm{b}}$ Clinic of Neonatology, Department Woman-Mother-Child, Lausanne University Hospital and University of Lausanne, Lausanne, Switzerland \\ ${ }^{c}$ Department Woman-Mother-Child, Lausanne University Hospital, Lausanne, Switzerland
}

\section{A R T I C L E IN F O}

\section{Article history:}

Received 26 September 2019

Received in revised form 30 January 2020

Accepted 7 July 2020

Available online $\mathrm{xxx}$

Keywords:

Discharge planning

Transitional care

Parents

Family

Intensive care

Neonatal

\section{A B S T R A C T}

\section{Background}

Discharge teaching has been positively associated with discharge readiness in various care settings and patient types. Association of discharge readiness with unplanned use of health services has not received as much attention in the neonatal intensive care unit (NICU) population, but has been negatively associated in parents of older children.

Objectives

The objective of the study was to describe and assess relationships between maternal readiness for neonates' discharge, discharge teaching, and unplanned use of health services after discharge from an NICU. Methods

Mothers from an NICU of a tertiary referral hospital in Switzerland completed the "Readiness for Hospital Discharge Scale" and the "Quality of Discharge Teaching Scale parental forms" in the $24 \mathrm{~h}$ preceding discharge. Telephone interviews evaluating the unplanned use of health services were conducted 28 days after discharge. Simple linear regressions and multiple regressions were used to explore the links between the readiness, perceived quality of discharge, and unplanned use of health services.

Results

Of the 71 participants, $75 \%(n=53 \%)$ felt ready for discharge when asked directly, and for $60 \%(n=42)$ of them, the amount of discharge teaching received was equal to or higher than that needed, but with high heterogeneity in scores. For $38 \%$ of mothers $(n=27)$, the expected support from the medical care of their child after discharge was deemed insufficient. In the month after discharge, unplanned use of health services occurred in $46 \%$ of the participants $(n=32)$. Perceived quality of teaching positively predicted readiness for discharge $\left(R^{2}=0.24, \mathrm{p}=0.0004\right)$. Unplanned use of health services correlated neither with readiness nor with perceived teaching quality. Conclusions

At discharge, mothers felt mostly ready and well prepared to go home. In the month after discharge, almost half used health services in an unplanned manner. Further exploration of reasons leading to this high rate of postdischarge healthcare utilisation is warranted.

(C) 2020

\section{Introduction}

Infants requiring care in a neonatal intensive care unit (NICU) are at higher risk of complex medical conditions and thus require complex care after discharge ${ }^{1-3}$. As a result, their parents suffer from emotional distress, depression, and anxiety at higher rates than parents of healthy infants and can develop altered parenting patterns on discharge home $\mathrm{H}^{4-8}$. These negative outcomes particularly affect

\footnotetext{
* Corresponding author at: Institute of Higher Education and Research in Healthcare, University of Lausanne, Biopôle 2, Route de la Corniche 10, Lausanne, Switzerland. Email address: laura.marques-rio@chuv.ch (L. Rio)
}

the mothers who are more likely to be the primary caretaker ${ }^{9-11}$. These infants also face higher risk of hospital readmission and death during the first year after birth ${ }^{12,13}$. Comprehensive discharge preparation, following the guidelines of the American Academy of Pediatrics (AAP) ${ }^{14}$, should increase readiness for discharge and lower negative outcomes such as unplanned and potentially preventable and costly hospital readmission in the first 30 days after hospital discharge ${ }^{15-20}$. The AAP guidelines include parental education, identification and involvement of support service, care planning in the hospital, and follow-up plan of care at home. In the past years, several programs, strategies, and interventions to specifically support parents or mothers have been developed to increase readiness, lower stress, and reduce emergency department attendances and associated costs. 
Some are mainly based on cognitive therapy and parent-oriented discharge education $^{21,22}$. Others aim to decrease parental stress with spiritual care ${ }^{23}$, mindfulness ${ }^{24}$, and relaxation ${ }^{25}$.

In our setting, there is no formal discharge program in place, yet nurses use a nine-item "Discharge checklist" based on the AAP recommendations, which includes medical and practical aspects of discharge that should be completed prior discharge. Added educational and medical information is given in a nonstandardised manner, according to the time and availabilities of both parents and health professionals. There is little evidence regarding parental perspectives of the NICU discharge process and postdischarge outcomes. Here, we wanted to evaluate the current discharge planning approach and its related outcomes to better assess the need for a specific program or intervention for discharge in our centre. Thus, the aim of this study was to describe discharge readiness and discharge teaching quality perceived by mothers of hospitalised neonates as well as the unplanned use of health services 1 month after discharge and to investigate associations between these three outcomes.

\section{Methods}

This cross-sectional correlational study was conducted in an NICU of a tertiary referral neonatology centre in Western Switzerland. The centre admits an average of 750 neonates each year, of whom approximately $300(40 \%)$ are directly discharged home. We recruited, using a convenience sampling method, adult mothers whose neonates were being discharged home and who were able to read and understand French. Mothers of twins or triplets participated once for the first child to be discharged. The Human Research Ethics Committee of the Canton of Vaud, Switzerland, approved this study, and informed consent was obtained from the participating mothers.

The maternal characteristics including age, nationality, social status, education level, employment status, number of children, and number of infants hospitalised in an NICU before and were assessed using a sociodemographic questionnaire. The neonates' characteristics were extracted from their medical file and included sex, gesta-

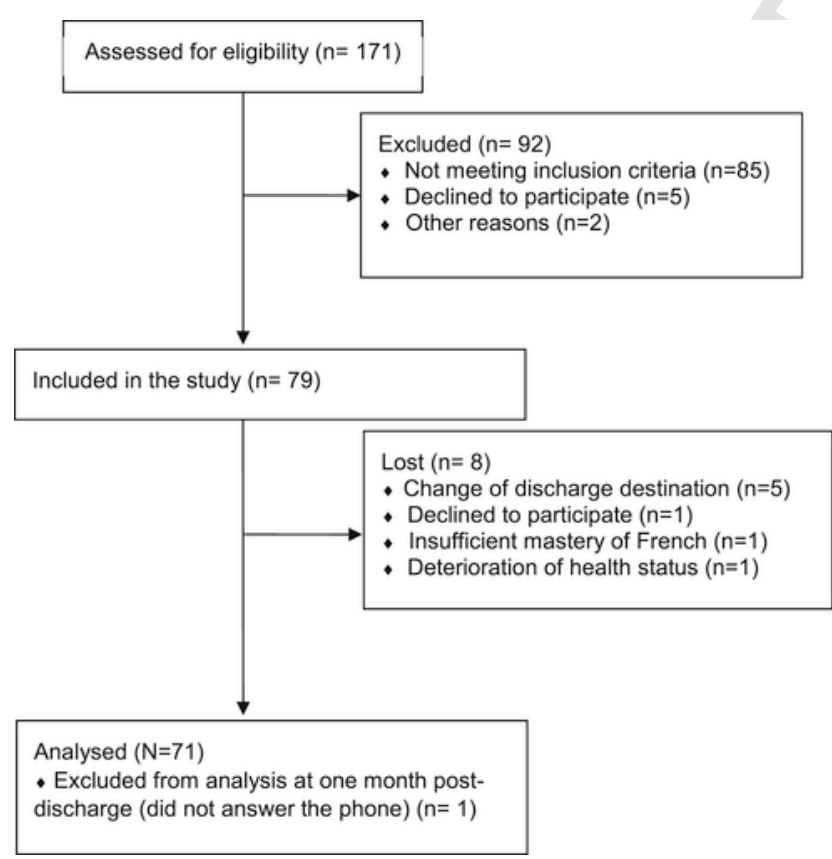

Fig. 1. Flow chart of participation. tional age, birth weight, weight at discharge, main reasons for NICU admission, and length of hospital stay.

At enrolment, during the $24 \mathrm{~h}$ before discharge, mothers completed the validated parental versions of the Readiness for Hospital Discharge Scale (RHDS) ${ }^{2}$ and the Quality of Discharge Teaching Scale (QDTS) ${ }^{2}$. The parental version of the RHDS measures the readiness for the transition from the NICU to home. It is composed of 29 items grouped in five subscales: (i) personal status of parent, (ii) personal status of child, (iii) knowledge, (iv) coping ability, and (v) expected support, scored on an 11-point scale (0-10) with anchor words (not at all and totally). Two additional items are "yes or no" questions querying readiness for hospital discharge: "As you think about your child going home from the hospital, do you feel you are ready to take your child home as planned?" and "Is your child ready to go home? The total maximum possible score for all items is 290 . A mean total score $\geq 203$ or single-item score $\geq 7$ indicates that the parent is ready for discharge home or ready for the specific domain of the corresponding subscale ${ }^{26}$.

The parental version of the QDTS measures educational preparation parent perception for discharge home. It is composed of 24 items, which are scored on an 11-point scale (0-10) with anchor words (none and a great deal). Items are grouped in three subscales: (i) content needed, (ii) content received, and (iii) content delivered. The content needed and received subscales focus on the amount of education received in six domains: information on the at-home care of the child, medical care treatment knowledge, practice with medical care, knowledge about when to call the provider, expected emotions, and family needs of other family members. The content delivered subscale addresses mainly content delivered by nurses in terms of information, listening, support, and empowerment of readiness for discharge. To evaluate perceived quality of teaching received alone, scores from the content received and content delivered subscales must be added $(b+c)$, and in this case, the maximum score is 180 and indicates a high perceived quality of teaching which meets the expectations of the participant. A differential score can be calculated by subtracting the scores of the content needed subscale from the scores of the content received subscale $(b-a)$ to assess the adequacy between these two contents, and the score can vary from -60 to 60 . Questionnaires were translated and adapted in French following the Principles of Good Practice for the Translation and Cultural Adaptation Process for Patient-Reported Outcomes Measures ${ }^{27}$.

The discharge process was evaluated by the completion of the "Discharge checklist" used in our centre. It contains nine items that should be completed by the time of discharge (Supplementary material)

Twenty-eight days after discharge, the mothers received a phone call from one of the investigators for evaluation of unplanned use of health services. The interview included five questions, the first three had a yes or no modality answer, and if the mothers had responded yes to at least one of them, specifics about the frequency and reasons of unplanned use were inquired in the two other questions (Supplementary material).

Statistical analyses were carried out using Stata/IC software, version 13.1 (StataCorp LLC, College Station, Texas, USA). Descriptive statistics were used for the variables relating to the demographic data, discharge readiness and perceived quality of teaching, and use of the healthcare system. We calculated means, standard deviations, and ranges for all the quantitative variables and frequencies and proportions for qualitative variables. As recommended by the authors ${ }^{2,28}$, the RHDS total score was calculated as a sum of all items. The subscale scores were also calculated similarly. Simple linear regressions and multiple regressions allowed us to explore the links between the readiness, quality of discharge, and unplanned use of the health system. The main sociodemographic characteristics described in the lit- 
erature that could impact readiness (i.e., age of the mother, parity, and level of education) were also tested using simple linear regressions. Point biserial correlations were used to analyse if the completed "Discharge checklist" would impact readiness or the unplanned use of hospital resources. In two of the collected RHDS questionnaires, wherein one item response was missing in one subscale, the missing item score was replaced by the mean subscale score, as per the recommendations of Weiss et al. ${ }^{2}$.

For analysis, the checklist was considered incomplete if one of the nine items was not filled in at the time of evaluation.

\section{Results}

Of the 171 mothers whose neonates were discharged from the NICU during the recruitment period, 85 did not meet the inclusion criteria, mostly because they had their neonates transferred to another hospital unit or other hospitals (see Fig 1.). Of the 86 mothers who were eligible, $71(82.6 \%)$ were enrolled. All participants completed the three questionnaires before discharge, and 70 responded to the follow-up telephone interview. For nearly half of the participants $(47.9 \%$; $\mathrm{n}=34$ ), the hospitalised neonate was their first child. Neonates were admitted in the NICU for one or more reasons, mainly for respiratory problems $(49.3 \% ; n=35)$ and/or for being premature $(40.9 \% ; n=29)$. Of the 71 mothers, $14 \%(n=10)$ had the nine items of the Discharge checklist completed, and they were documented $24 \mathrm{~h}$ preceding discharge. Characteristics of the study population and Discharge checklist outcomes are reported in Table 1.

In response to the questions "As you think about your child going home from the hospital, do you feel you are ready to take your child home as planned?" and "Is your child ready to go home?", most mothers answered "yes" $(97 \%, n=69 ; 94 \%, n=67)$, indicating that they felt mostly ready to go home when asked directly.

The RHDS total scores ranged from 116 to 273, and most mothers felt ready for discharge with mean scores higher than the cut-off point of $7(75 \%, n=53)$. The item mean score varied in the four subscales and was higher than the threshold for three items: "personal status" with 7.5 for the parent $(>7 ; 65 \%, \mathrm{n}=46)$ and 7.9 for the child $(>7$; $86 \%, \mathrm{n}=61)$, "knowledge" with $7.6(>7 ; 75 \%, \mathrm{n}=53)$, and "coping ability" with $8.3(>7 ; 90 \%, \mathrm{n}=64)$.

The "expected support" subscale item mean score was below the threshold, with more than a third of mothers feeling that they would not receive sufficient support at home; the proportion of scores less than 7 was $36 \%(n=26)$. More specifically, of the four items in the expected support subscale, the item "How much help will you have with household activities (for example, cooking, cleaning, shopping, babysitting)" had a mean item score of $6.7(<7 ; 35 \%, n=25)$ and the item "How much help will you have with your child's medical care needs (treatments, medications) after you go home?" had a mean item score of $6.1(<7 ; 38 \%, \mathrm{n}=27)$. The QDTS subscale scores ranged from 4 to 57 for the "content needed" subscale, from 0 to 60 for the "content received" subscale, and from 54 to 120 (mean =96; standard deviation $=16$ ) for the "content delivered" subscale. With regard to quality of teaching received, the added score of "content received" and "content delivered" ranged from 54 to 178. The mean differential score between "content needed" and "content received" ranged from -26 to 39 , indicating that the content received was very slightly superior to the content needed. Summary of readiness and quality of teaching perceived scores are reported in Table 2.

One month after discharge, telephone interviews were conducted, which lasted from 2 to 28 min $($ mean $=5$, standard deviation $=5)$. Nearly half of the mothers $(46 \% ; n=32)$ had made unplanned use of healthcare services (Table 3 ). Some mothers had more than one unplanned use, and altogether, 48 unplanned medical consultations were reported, almost half of which were visits to the paediatrician
Table 1

Characteristics of the study population and Discharge checklist outcomes.

\begin{tabular}{|c|c|c|}
\hline Characteristic & $\mathrm{n}$ & $\%$ \\
\hline \multicolumn{3}{|l|}{ Maternal education } \\
\hline No qualification & 3 & 4.2 \\
\hline Primary school & 21 & 29.6 \\
\hline Secondary school & 16 & 22.5 \\
\hline University diploma or more & 31 & 43.7 \\
\hline \multicolumn{3}{|l|}{ Professional activity rate $*$} \\
\hline Stay-at-home mothers & 14 & 19.7 \\
\hline Part-time & 24 & 33.8 \\
\hline Full-time & 44 & 46.5 \\
\hline \multicolumn{3}{|l|}{ Parity } \\
\hline First child & 34 & 47.9 \\
\hline Second or more & 37 & 52.1 \\
\hline \multicolumn{3}{|l|}{ Maternal age (years) } \\
\hline$<25$ & 7 & 9.5 \\
\hline $25-35$ & 41 & 57.7 \\
\hline $35-39$ & 16 & 22.5 \\
\hline$\geq 40$ & 7 & 9.5 \\
\hline \multicolumn{3}{|l|}{ Marital status } \\
\hline Single & 6 & 8.5 \\
\hline Married & 17 & 23.9 \\
\hline In a relationship & 48 & 67.6 \\
\hline \multicolumn{3}{|l|}{ Mother's country of birth } \\
\hline Swiss & 40 & 56.3 \\
\hline European & 22 & 31.0 \\
\hline Other & 9 & 12.7 \\
\hline \multicolumn{3}{|l|}{ Infant sex } \\
\hline Male & 37 & 52.1 \\
\hline Female & 34 & 47.9 \\
\hline \multicolumn{3}{|l|}{ Gestational age (completed weeks) } \\
\hline$<32$ & 4 & 5.6 \\
\hline $32-36$ & 25 & 35.5 \\
\hline$\geq 37$ & 42 & 59.6 \\
\hline \multicolumn{3}{|l|}{ Length of NICU stay (days) } \\
\hline$<15$ & 42 & 59.2 \\
\hline $15-28$ & 19 & 26.8 \\
\hline$>28$ & 10 & 14.1 \\
\hline \multicolumn{3}{|l|}{ Discharge checklist completed } \\
\hline Yes & 10 & 14.1 \\
\hline No & 61 & 85.9 \\
\hline \multicolumn{3}{|l|}{ Items completed in the checklist } \\
\hline Lactation & 52 & 73.2 \\
\hline Health record to the paediatrician & 60 & 84.5 \\
\hline Name of the paediatrician & 67 & 94.4 \\
\hline General assessment & 25 & 35.2 \\
\hline Specific assessment & 68 & 95.8 \\
\hline Car seat instructions & 25 & 35.2 \\
\hline Discharge interview & 27 & 38.0 \\
\hline Health records to parents & 14 & 19.7 \\
\hline Medical prescriptions & 14 & 19.7 \\
\hline
\end{tabular}

$\mathrm{NICU}=$ neonatal intensive care unit.

$(42 \% ; n=20)$. Three infants were readmitted to the hospital once, and one was readmitted to the hospital twice. Reasons for consulting were diverse, with a majority related to digestion and feeding issues $(62.5 \% ; \mathrm{n}=30)$. In addition to the standardised interview questions, one of five $(20 \%, n=15)$ participants spontaneously reported the need for support from their peers or healthcare professionals for coping with everyday life since discharge.

Association analysis has demonstrated that the association between readiness for discharge and perceived quality of discharge teaching was statistically significant $(\mathrm{p}=0.002)$ and perceived quality of discharge teaching explained $13 \%\left(R^{2}=0.13\right)$ of the variance in readiness for hospital discharge $(\beta=0.41)$. The association between readiness for discharge and content delivered was also statistically significant $(\mathrm{p}<0.001)$ and content delivered explained $18 \%\left(R^{2}=0.18\right)$ of the variance in readiness for hospital discharge $(\beta=0.78)$. Other tested associations were not statistically signifi- 
Table 2

Summary of RHDS and QDTS scoring $(\mathrm{N}=71)$.

\begin{tabular}{|c|c|c|c|c|}
\hline Scale & $\begin{array}{l}\text { Number } \\
\text { of items }\end{array}$ & $\begin{array}{l}\text { Scale } \\
\text { mean } \\
(\mathrm{SD})\end{array}$ & $\begin{array}{l}\text { Item } \\
\text { mean }\end{array}$ & $\begin{array}{l}\text { Range } \\
\text { (minimum-maximum) }\end{array}$ \\
\hline \multicolumn{5}{|l|}{ RHDS } \\
\hline Total scale & 29 & $\begin{array}{l}221.2 \\
(29.5)\end{array}$ & 7.6 & $116-273$ \\
\hline \multicolumn{5}{|c|}{ Personal Status subscale } \\
\hline Parent & 7 & $\begin{array}{l}52.2 \\
(49)\end{array}$ & 7.5 & $19-67$ \\
\hline Child & 6 & $\begin{array}{l}47.5 \\
(42)\end{array}$ & 7.9 & $25-60$ \\
\hline $\begin{array}{l}\text { Knowledge } \\
\text { subscale }\end{array}$ & 9 & $\begin{array}{l}68.8 \\
(63)\end{array}$ & 7.6 & $23-90$ \\
\hline $\begin{array}{l}\text { Coping Ability } \\
\text { subscale }\end{array}$ & 3 & $\begin{array}{l}24.9 \\
(21)\end{array}$ & 8.3 & $11-30$ \\
\hline $\begin{array}{l}\text { Expected } \\
\text { Support } \\
\text { subscale }\end{array}$ & 4 & $\begin{array}{l}\mathbf{2 7 . 8 ^ { \mathrm { a } }} \\
(28)\end{array}$ & $6.9^{a}$ & $1-40$ \\
\hline \multicolumn{5}{|l|}{ QDTS } \\
\hline $\begin{array}{l}\text { Total scale } \\
(\mathrm{a}+\mathrm{b})\end{array}$ & 18 & $\begin{array}{l}129.4 \\
(26)\end{array}$ & 7.2 & $54-178$ \\
\hline $\begin{array}{l}\text { (a) Content } \\
\text { delivered }\end{array}$ & 12 & $\begin{array}{l}96.3 \\
(15.7)\end{array}$ & 8 & $54-120$ \\
\hline $\begin{array}{l}\text { (b) Content } \\
\text { received }\end{array}$ & 6 & $\begin{array}{l}33.4 \\
(13.8)\end{array}$ & 5.6 & $0-60$ \\
\hline $\begin{array}{l}\text { (c) Content } \\
\text { needed }\end{array}$ & 6 & $\begin{array}{l}31.4 \\
(13.1)\end{array}$ & 5.2 & $4-57$ \\
\hline $\begin{array}{l}\text { Differential } \\
\text { scale }(b-c)\end{array}$ & 12 & $\begin{array}{l}2 \\
(11.4)\end{array}$ & NA & $-26-39$ \\
\hline
\end{tabular}

RHDS $=$ Readiness $\quad$ for Hospital Discharge Scale, QDTS $=$ Quality of Discharge Teaching Scale, $\mathrm{SD}=$ standard deviation, $\mathrm{NA}=$ not applicable.

${ }^{\text {a }}$ Values below the threshold.

Table 3

Unplanned use of health services during the $28 \mathrm{~d}$ after discharge $(\mathrm{N}=70)$.

\begin{tabular}{lll}
\hline Telephone interview & Frequency & Proportion $^{\mathrm{a}}$ \\
\hline $\begin{array}{l}\text { Answered the phone evaluation }(\mathbf{n}=\mathbf{7 0}) \\
\text { Answered yes for }\end{array}$ & 32 & 45.7 \\
unplanned use & \\
Answered no for & 38 & 54.3 \\
unplanned use & & \\
Had unplanned consultations $(\mathbf{n}=\mathbf{4 8})$ & 41.7 \\
Visit to the paediatrician & 20 & 31.2 \\
Phone call consultation & 15 & 27.1 \\
Visit to the emergencies of & 13 & \\
the hospital & & \\
Total of unplanned consultations $(\mathrm{n}=48)$ & 39.5 \\
One & 19 & 28.8 \\
Two & 10 & 4.3 \\
Three & 3 & 62.5 \\
Reasons for consultation $(\mathbf{n}=\mathbf{4 8 )}$ & 25 \\
Digestive & 30 & 12.5 \\
Respiratory & 12 & 75 \\
Wounds or others & 6 & 25 \\
Number of times the infants were rehospitalised $(\mathbf{n}=\mathbf{4})$ \\
Once & 3 & \\
Twice & 1 & \\
\hline
\end{tabular}

${ }^{\text {a }}$ Calculated on the total number for the item measured.

cant. Predictors of readiness for discharge and unplanned use of health services are presented in Table 4.

\section{Discussion}

This study addressed an important yet understudied issue, discharge preparation of mothers who had a neonate hospitalised in the NICU and returned home. Our results showed that when asked directly, mothers felt ready to go home and well taught, but when more specific questions were asked, they felt unready in some ar-
Table 4

Predictors of discharge readiness and unplanned use of health services after discharge.

\begin{tabular}{|c|c|c|c|c|c|c|}
\hline & $\mathrm{n}$ & $\begin{array}{l}R^{2}, \\
\%\end{array}$ & $\begin{array}{l}\text { Coefficient } \\
\text { beta } * \text { correlation } * *\end{array}$ & $95 \% \mathrm{CI}$ & & $\begin{array}{l}\mathrm{p}- \\
\text { value }\end{array}$ \\
\hline \multicolumn{7}{|c|}{ Predictors of readiness for discharge } \\
\hline $\begin{array}{l}\text { Perceived } \\
\text { quality of } \\
\text { discharge } \\
\text { teaching }\end{array}$ & 69 & 13 & $0.41 *$ & 0.15 & -0.66 & 0.002 \\
\hline $\begin{array}{l}\text { Content } \\
\text { needed }\end{array}$ & 69 & 1 & $-0.23 *$ & -0.77 & -0.32 & 0.408 \\
\hline $\begin{array}{l}\text { Content } \\
\text { received }\end{array}$ & 69 & 3.8 & $0.41 *$ & -0.1 & -0.93 & 0.111 \\
\hline $\begin{array}{l}\text { Content } \\
\text { delivered }\end{array}$ & 70 & 18 & $0.78 *$ & 0.37 & -1.19 & $<0.001$ \\
\hline $\begin{array}{l}\text { Maternal } \\
\text { age }\end{array}$ & 70 & 0 & $0.167 *$ & -1.12 & 1.45 & 0.796 \\
\hline Parity & 70 & 0 & $-0.974 *$ & -7.5 & 7.31 & 0.979 \\
\hline Education & 70 & 0 & $5.9 *$ & -1.43 & 13.24 & 0.113 \\
\hline $\begin{array}{l}\text { Checklist } \\
\text { completed }\end{array}$ & 70 & & $-0.18 * *$ & & & 0.1157 \\
\hline \multicolumn{7}{|c|}{ Predictors of unplanned use of health services } \\
\hline $\begin{array}{l}\text { Perceived } \\
\text { quality of } \\
\text { discharge } \\
\text { teaching }\end{array}$ & 69 & 0 & $-2.56 *$ & -9.79 & 4.67 & 0.482 \\
\hline Readiness & 69 & 0 & $2.3 *$ & -5.99 & -10.6 & 0.581 \\
\hline $\begin{array}{l}\text { Checklist } \\
\text { completed }\end{array}$ & 70 & & $0.09 * *$ & & & 0.411 \\
\hline
\end{tabular}

$\mathrm{CI}=$ confidence interval. $\mathrm{p}$-values in bold are $<0.05 .{ }^{*}=$ coefficient beta, ${ }^{* *}=$ correlation

eas. Specifically, expected support at home was deemed insufficient, especially regarding the medical care needs of their infants and household activities. In addition, we observed an unusually high proportion of unplanned use of health services in the month after discharge.

Our sample included mostly European, married, and highly educated women, which corresponds to sociodemographics of parents in other European reports ${ }^{29,30}$. Their overall discharge readiness scores indicated that they felt ready for discharge overall, which is congruent with the current scientific literature ${ }^{2,31}$. In our study, the "expected support" scores were below the threshold for $36 \%$ of the participants, indicating insufficient expected support that has not been described by others ${ }^{2,31}$. Support was deemed insufficient in the household and in medical care needs of the infants. Insufficient household support could be linked with the Swiss culture, wherein familial support is mainly expected from the nuclear family and less support is sought from the extended family or friends, who are a potential source of support ${ }^{32,33}$. Insufficient medical support to take care of mothers' infants was measured in more than a third of our sample, indicating that insufficient support in care continuity was perceived by these mothers in transition from the NICU to home. In the literature, unreadiness for discharge has been linked with factors such as substance abuse, inadequate prenatal care, teenage pregnancy, domestic violence, marital instability, mental health issues, lower socio-economic status, low health literacy, and insufficient mastery of language ${ }^{34-39}$. The participants in our study had none of these apparent risk factors. To the contrary, they reported high socio-economic status and literacy and were all adults during pregnancy. The other potential factors such as mental health were not investigated and thus cannot be precluded. Discharge readiness has also been associated with being a first-time mother and not being able to rely on previous parenting experiences ${ }^{2}$, but this was not the case in our study. Complexity of the health of the infant could also be foreseen as a factor influencing mothers' readiness and/or unplanned use of health- 
care services, but assessment of this factor was not included in the scope of this study.

Overall, the perceived quality of discharge teaching was good in our study. As in other studies, we observed a wide range of total scores, indicating that the perceived quality of discharge teaching was different amongst all mothers 2,31 . This disparity in scores was also reflected in the differential scores between the teaching needed and received, thus indicating that some mothers had received more information than what they needed or, conversely, some had not received enough information, i.e., those with negative scores. As observed in other studies, readiness for discharge was partially explained by the perceived quality of teaching received, underlining the need for appropriate discharge teaching that meets individual needs $\mathrm{s}^{2,31}$.

Postdischarge unplanned use of health services affected $46 \%$ of the mothers in our sample, which is the double of what Weiss et al. ${ }^{2}$ had observed in their US study evaluating parents of hospitalised children who experienced $23.4 \%$ of unscheduled use of healthcare services during the month after home discharge. What is also worth noting is that in the study by Weiss et al. ${ }^{2}$, the rehospitalisation rate was $15.1 \%$; in our study, it was $5.7 \%$, indicating that in the US study, two-thirds of unplanned consultations led to rehospitalisation, and in our Swiss sample, rehospitalisation was described in just more than one-tenth of the unplanned use cases. Reasons for consulting in our study were, however, very similar to those found in the literature, mainly with digestive and respiratory reasons for consultation ${ }^{2,14,40,41}$. In the literature, the link between low readiness and postdischarge difficulties has been demonstrated ${ }^{42}$. However, in our study, we did not find a correlation between discharge readiness and unplanned use of health services. Other factors involved in unplanned admission are multiple and might include clinical factors such as prematurity, sociocultural factors, access to care, and financial pressure for shorter hospital stays in the health system, but we did not evaluate these factors in our study.

Functioning of the health system and access to care could also play a role. As health insurance is mandatory in Switzerland and most mothers participating in this study had a high socio-economic status, we could argue that more use of the healthcare system in our sample was due to higher accessibility to care for mothers in Switzerland than in other European countries ${ }^{43}$. It could also be hypothesised that mothers who felt unsupported at home sought support by consulting in an unplanned manner. The fear of receiving insufficient support both with care of their infant and with the household, measured using the RHDS prior discharge, was confirmed by $20 \%$ of mothers during the phone interview, who reported, without being asked, that they felt not supported enough both emotionally and practically. This need for support might also explain the exceptionally high proportion of mothers (99\%) who completed the phone interview 1 month after the first and only contact with the investigator.

Evaluation of the completeness of the "Discharge checklist" showed that some items were not completed until immediately before discharge, thus indicating that some strategies to provide a more timely delivery of these items could be implemented. It is worth noting that the completeness of the checklist did not predict readiness or unplanned use of health services. As the checklist evaluates general elements that should be carried out before discharge, additional measures that would be specific and individualised to each mother-infant dyad might be beneficial.

Limitations of our study included some dimensions intrinsic to our study design and population. First, for feasibility reasons, we included only mothers; thus, we only have a limited perspective of the family. It would be recommended for future research to include at a minimum the paternal perspective, if not the family perspective. A second limitation is the sample size, which was not large enough to establish a significant correlation with sociodemographics of mothers and the infants' medical factors and with readiness, perceived quality of teaching, and unplanned use of the healthcare system after discharge. Finally, factors involved in the large variability of responses and use of the health system are neither explained in our study nor explored in the literature; exploration of those factors for future research is warranted.

\section{Conclusions}

Mothers felt unready to take care of the medical need of their children, and thus, it is important to reinforce their preparation and confidence to become primary caretakers during the discharge preparation. The large heterogeneity observed in our sample indicates that at discharge, feelings of readiness and quality of discharge teaching received varied tremendously amongst mothers. Screening of mothers feeling unready or/and insufficiently taught for discharge should be performed, and individualised teaching and preparation should be implemented to bridge that gap. The "Discharge checklist" and nonstandardised discharge information given to the mothers could be completed by evidence-based specific discharge programs or interventions. Postdischarge use of health service indicated that despite feeling ready and well taught, mothers did use the healthcare system in an unplanned way quite extensively. Enhanced support services before and after discharge should be considered to improve readiness and confidence in mothers to take care of their babies after discharge. Further research, including fathers and families, is warranted.

\section{CRediT authorship contribution statement}

Laura Rio: Conceptualization, Formal analysis, Methodology, Project administration, Supervision, Validation, Writing - original draft. Chloé Tenthorey: Data curation, Formal analysis, Investigation, Software, Visualization, Writing - original draft. Anne-Sylvie Ramelet: Conceptualization, Methodology, Project administration, Resources, Supervision, Validation, Writing - review $\&$ editing.

\section{Conflict of interest}

None.

\section{Appendix A. Supplementary data}

Supplementary data to this article can be found online at https:// doi.org/10.1016/j.aucc.2020.07.001.

\section{References}

[1] E. Enlow, et al., Neonatal intensive care unit to home: the transition from parent and pediatrician perspectives, a prospective cohort study, J Perinatol 34 (2014) 761.

[2] M. Weiss, et al., Readiness for discharge in parents of hospitalized children, J Pediatr Nurs 23 (4) (2008) 282-295.

[3] S.W. Patrick, et al., Risk of hospital readmission among infants with neonatal abstinence syndrome, Hosp Pediatr 5 (10) (2015) 513-519.

[4] S. Johnson, et al., Randomised trial of parental support for families with very preterm children: outcome at 5 years, Arch Dis Child 90 (9) (2005) 909-915

[5] J. Pinelli, Effects of family coping and resources on family adjustment and parental stress in the acute phase of the NICU experience, Neonatal Netw 19 (6) (2000) 27-37.

[6] R. Harris, et al., Maternal mental health during the neonatal period: relationships to the occupation of parenting, Early Hum Dev 120 (2018) 31-39.

[7] C. Ionio, et al., Mothers and fathers in NICU: the impact of preterm birth on parental distress, Eur J Psychol 12 (4) (2016) 604-621.

[8] N.N. Tahirkheli, et al., Postpartum depression on the neonatal intensive care unit: current perspectives, Int J Womens Health 6 (2014) 975-987. 
[9] L.C. Howland, et al., Exploring biobehavioral outcomes in mothers of preterm infants, MCN Am J Matern/Child Nurs 36 (2) (2011) 91-97.

[10] A. Aftyka, et al., Risk factors for the development of post-traumatic stress disorder and coping strategies in mothers and fathers following infant hospitalisation in the neonatal intensive care unit, J Clin Nurs 26 (23-24) (2017) 4436-4445.

[11] C. Ionio, et al., Premature birth: complexities and difficulties in building the mother-child relationship, J Reprod Infant Psychol 35 (5) (2017) 509-523.

[12] T.C. Hulsey, M.B. Hudson, W.B. Pittard 3rd, Predictors of hospital postdischarge infant mortality: implications for high-risk infant follow-up efforts, J Perinatol 14 (3) (1994) 219-225.

[13] V.C. Smith, et al., Rehospitalization in the first year of life among infants with bronchopulmonary dysplasia, J Pediatr 144 (6) (2004) 799-803.

[14] American Academy of Pediatrics, Committee on Fetus and Newborn, Hospital discharge of the high-risk neonate, Pediatrics 122 (5) (2008) 1119-1126.

[15] V.C. Smith, et al., Neonatal intensive care unit discharge preparation, family readiness and infant outcomes: connecting the dots, J Perinatol 33 (6) (2013) 415-421.

[16] L. Smith, H. Daughtrey, Weaving the seamless web of care: an analysis of parents' perceptions of their needs following discharge of their child from hospital, J Adv Nurs 31 (4) (2000) 812-820.

[17] D.B. Danbjorg, L. Wagner, J. Clemensen, Do families after early postnatal discharge need new ways to communicate with the hospital? A feasibilility study, Midwifery 30 (6) (2014) 725-732.

[18] A.L. Jefferies, Canadian Paediatric Society, Fetus and Newborn Committee, Going home: Facilitating discharge of the preterm infant, Paediatr Child Health 19 (1) (2014) 31-42.

[19] M.M. Mills, D.C. Sims, J. Jacob, Implementation and case-study results of potentially better practices to improve the discharge process in the neonatal intensive care unit, Pediatrics 118 (Suppl 2) (2006) S124-S133.

[20] L. Jing, C.N. Bethancourt, T. McDonagh, Assessing infant and maternal readiness for newborn discharge, Curr Opin Pediatr 29 (5) (2017) 598-605.

[21] Y. Liu, et al., Transition home plus program reduces medicaid spending and health care use for high-risk infants admitted to the neonatal intensive care unit for 5 or more days, J Pediatr 200 (2018) 91-97 e3.

[22] B. Vohr, et al., Impact of a transition home program on rehospitalization rates of preterm infants, J Pediatr 181 (2017) 86-92 e1.

[23] D. Kucuk Alemdar, F. Kardas Ozdemir, F. Guducu Tufekci, The effect of spiritual care on stress levels of mothers in NICU, West J Nurs Res 40 (7) (2018) $997-1011$.

[24] T. Mendelson, et al., A mindfulness intervention to reduce maternal distress in neonatal intensive care: a mixed methods pilot study, Arch Womens Ment Health (2018).

[25] L.C. Howland, et al., Feasibility of a relaxation guided imagery intervention to reduce maternal stress in the NICU, J Obstet Gynecol Neonatal Nurs 46 (4) (2017) 532-543.
[26] K.L. Bobay, et al., Age-related differences in perception of quality of discharge teaching and readiness for hospital discharge, Geriatr Nurs 31 (3) (2010) $178-187$.

[27] D. Wild, et al., Principles of good practice for the translation and cultural adaptation process for patient-reported outcomes (PRO) measures: report of the ISPOR task force for translation and cultural adaptation, Value Health 8 (2) (2005) 94-104.

[28] M.E. Weiss, L.B. Piacentine, Psychometric properties of the readiness for hospital discharge scale, J Nurs Meas 14 (3) (2006) 163-180.

[29] I.H. Hagen, et al., Parental satisfaction with neonatal intensive care units: a quantitative cross-sectional study, BMC Health Serv Res 19 (1) (2019) 37.

[30] R.F. Maier, et al., Duration and time trends in hospital stay for very preterm infants differ across European regions, Pediatr Crit Care Med 19 (12) (2018) 1153-1161.

[31] Y. Chen, J. Zhang, J. Bai, Effect of an educational intervention on parental readiness for premature infant discharge from the neonatal intensive care units, $\mathrm{J}$ Adv Nurs 72 (1) (2016) 135-146.

[32] L. Bernardi, J.-M. Le Goff, Ryser, Gender role-set, family orientations, and fertility intentions in Switzerland, Swiss J Sociol (2013).

[33] Federal Statistical Office, Families in Switzerland. The 2017 statistical report, 2017 https://www.bfs.admin.ch/bfs/en/home/statistics/catalogues-databases/ publications.assetdetail.2347881.html

[34] F. Miquel-Verges, P.K. Donohue, R.D. Boss, Discharge of infants from NICU to Latino families with limited English proficiency, J Immigr Minority Health 13 (2) (2011) 309-314.

[35] E. Enlow, et al., Perspectives of low socioeconomic status mothers of premature infants, Pediatrics 139 (3) (2017).

[36] A. Fatmawati, I. Nur Rachmawati, T. Budiati, The influence of adolescent postpartum women's psychosocial condition on mother-infant bonding, Enferm Clin 28 (Suppl 1) (2018) 203-206.

[37] M. Parolin, A. Simonelli, Attachment theory and maternal drug addiction: the contribution to parenting interventions, Front Psychiatr 7 (2016) 152.

[38] A. Santona, et al., Maternal depression and attachment: the evaluation of mother-child interactions during feeding practice, Front Psychol 6 (2015) 1235

[39] M.L. Urquia, et al., Experiences of violence before and during pregnancy and adverse pregnancy outcomes: an analysis of the Canadian Maternity Experiences Survey, BMC Pregnancy Childbirth 11 (2011) 42.

[40] V.C. Smith, et al., Neonatal intensive care unit discharge preparedness: primary care implications, Clin Pediatr 51 (5) (2012) 454-461.

[41] N. Sneath, Discharge teaching in the NICU: are parents prepared? An integrative review of parents' perceptions, Neonatal Netw 28 (4) (2009) 237-246.

[42] H.H. Bernstein, et al., Postpartum discharge: do varying perceptions of readiness impact health outcomes?, Ambul Pediatr 2 (5) (2002) 388-395.

[43] C. De Pietro, et al., Switzerland: health system review, Health Syst Transit 17 (4) (2015) 1-288, [xix] 